\title{
Electrospun Carbon Nanofibers with Embedded Co-Ceria Nanoparticles for Efficient Hydrogen Evolution and Overall Water Splitting
}

\author{
Seongwon Woo ${ }^{1}$, Jooyoung Lee ${ }^{1}$, Dong Sub Lee ${ }^{1}$, Jung Kyu Kim ${ }^{2, *}$ and Byungkwon Lim ${ }^{1, *}$ \\ 1 School of Advanced Materials Science and Engineering, Sungkyunkwan University (SKKU), Suwon 16419, \\ Korea; wsw0601@skku.edu (S.W.); ljy5424@skku.edu (J.L.); leedongsub92@gmail.com (D.S.L.) \\ 2 School of Chemical Engineering, Sungkyunkwan University (SKKU), Suwon 16419, Korea \\ * Correspondence: legkim@skku.edu (J.K.K.); blim@skku.edu (B.L.)
}

Received: 24 December 2019; Accepted: 11 February 2020; Published: 13 February 2020

check for updates

\begin{abstract}
In this study, simple electrospinning combined with pyrolysis were used to fabricate transition-metal-based-nanoparticle-incorporated carbon nanofiber (CNF) electrocatalysts for a high-efficiency hydrogen evolution reaction (HER) and overall water splitting. $\mathrm{Co}-\mathrm{CeO}_{2}$ nanoparticle-incorporated carbon nanofibers $\left(\mathrm{Co}-\mathrm{CeO}_{2} @ \mathrm{CNF}\right)$ exhibit an outstanding electrocatalytic HER performance with an overpotential and Tafel slope of $92 \mathrm{mV}$ and $54 \mathrm{mV} / \mathrm{dec}$, respectively. For the counterpart, electrolysis, we incorporate the widely used $\mathrm{Ni}_{2} \mathrm{Fe}$ catalyst with a high oxygen evolution reaction (OER) activity into the carbon nanofiber $\left(\mathrm{Ni}_{2} \mathrm{Fe} @ \mathrm{CNF}\right)$. To evaluate their electrochemical properties for the overall water splitting, $\mathrm{Co}-\mathrm{CeO}_{2} @ \mathrm{CNF}$ and $\mathrm{Ni}_{2} \mathrm{Fe} @ \mathrm{CNF}$ were used as the HER and OER electrocatalysts in an alkaline electrolyzer. With the paired $\mathrm{Co}-\mathrm{CeO}_{2} @ \mathrm{CNF}$ and $\mathrm{Ni}_{2} \mathrm{Fe} @ \mathrm{CNF}$ electrodes, an overall water splitting current density of $10 \mathrm{~mA} / \mathrm{cm}^{2}$ was achieved by applying $1.587 \mathrm{~V}$ across the electrodes with a remarkably lower overpotential of $257 \mathrm{mV}$ compared to that of an electrolyzer comprised of $\mathrm{Pt} / \mathrm{C}$ and $\mathrm{IrO}_{2}$ electrodes $(400 \mathrm{mV})$. Owing to the conformal incorporation of nanoparticles into the $\mathrm{CNF}$, the electrocatalysts exhibit significant long-term durability over $70 \mathrm{~h}$ of overall water splitting. This study provides rational designs of catalysts with high electrochemical catalytic activity and durability to achieve overall water splitting.
\end{abstract}

Keywords: electrospinning; carbon nanofiber support; overall water splitting; transition-metal-based electrocatalysts

\section{Introduction}

The fabrication of high-efficiency catalysts with long-term durability through a cost-effective process is essential for the sustainable production of hydrogen $\left(\mathrm{H}_{2}\right)$ [1,2]. Electro-chemical water splitting has been considered as a promising eco-friendly process that avoids the emission of greenhouse gases or harmful components (i.e., $\mathrm{CO}_{2}$ or $\mathrm{NO}_{x}$ ) [2,3]. In recent decades, several studies have been performed to replace noble-metal-based electrocatalysts with earth-abundant nonnoble metals and highly active materials such as transition-metal alloys, oxides, carbides, nitrides, and phosphides [4-15]. However, various issues need to be addressed to achieve high-efficiency overall water electrolysis. Such issues include the poor electrochemical catalytic kinetics with very high overpotentials on both electrocatalysts for the simultaneous hydrogen evolution reaction (HER) and oxygen evolution reaction (OER) $[4,16]$. Moreover, several durability issues exist regarding electrocatalysts during electrolysis. Even commercialized $\mathrm{Pt} / \mathrm{C}$ and $\mathrm{Pt}$ alloys suffer from degradation in the electrolyte [17]. To improve the long-term stabilities of the catalysts, highly conductive carbon-based nanomaterials such as carbon nanotubes, reduced graphene oxide, and carbon nanofibers (CNFs) have been utilized as support 
or binding materials [18-20]. However, conformal incorporations of nanostructured catalysts into nanocarbon-based supports with a systemic formation should be realized to simultaneously ensure the sufficient electrochemical activity and high conductance of the carriers [20,21]. Therefore, the rational design of electrocatalysts, considering the process cost, catalytic activity, and long-term durability, is required to achieve high-efficiency overall water splitting for the production of clean $\mathrm{H}_{2}$. Recently, cost-effective electrospun nanofibers with a high conductivity and a large specific surface area have attracted considerable attention for electrochemical HER [22-24]. The highly conductive nanofibers obtained by electrospinning can be an excellent support for electrocatalysts owing to their outstanding mechanical strength, flexibility, and charge-transport properties [24-26].

In this study, simple electrospinning combined with pyrolysis were utilized to fabricate transition-metal-incorporated CNF electrocatalysts for efficient HER and overall water splitting. Cobalt-incorporated ceria $\left(\mathrm{CeO}_{2}\right)$ nanoparticles on a conductive carbon nanofiber $\left(\mathrm{Co}-\mathrm{CeO}_{2} @ \mathrm{CNF}\right)$ were fabricated for HER. Owing to the abundant defect sites originating from oxygen vacancies and the favorable conversion of oxidation states between $\mathrm{Ce}^{3+}$ and $\mathrm{Ce}^{4+}, \mathrm{CeO}_{2}$ can be considered as an excellent support for cobalt to achieve increased electrochemical activity and good stability [21,27-30]. $\mathrm{Co}-\mathrm{CeO}_{2}$ nanoparticles with an atomic Co:Ce ratio of 1:1 were homogeneously dispersed on the CNF supports, which provided outstanding electrocatalytic performance. For the counterpart, water electrolysis, the widely used $\mathrm{Ni}_{2} \mathrm{Fe}$ catalyst for OER was incorporated into the CNF. To evaluate their electrochemical properties for the overall water splitting, $\mathrm{Co}-\mathrm{CeO}_{2} @ \mathrm{CNF}$ and $\mathrm{Ni}_{2} \mathrm{Fe} @ \mathrm{CNF}$ were used as the HER and OER electrocatalysts in an alkaline electrolyzer, respectively. Their performances were compared with those of an electrolyzer fabricated by pairing $\mathrm{Pt} / \mathrm{C}$ and $\mathrm{IrO}_{2}$ electrodes. With the paired $\mathrm{Co}-\mathrm{CeO}_{2} @ \mathrm{CNF}$ and $\mathrm{Ni}_{2} \mathrm{Fe} @ \mathrm{CNF}$ electrodes, an overall water splitting current density of $10 \mathrm{~mA} / \mathrm{cm}^{2}$ was achieved by applying $1.587 \mathrm{~V}$ across the electrodes with lower overpotential of $257 \mathrm{mV}$. Owing to the conformal incorporation of nanoparticles into the CNF supports, the electrocatalysts exhibited significant long-term durability over $70 \mathrm{~h}$ of operation.

\section{Materials and Methods}

\subsection{Synthesis of Electrocatalysts}

For the typical electrospinning synthesis, $1.0 \mathrm{~g}$ of polyacrylonitrile (PAN, average $M_{\mathrm{W}}=150,000$, Sigma-Aldrich, Missouri, USA) was initially dissolved in N,N-dimethylformamide (Deajung) solvent $(10 \mathrm{~mL})$ under vigorous stirring for $6 \mathrm{~h}$. To fabricate $\mathrm{Co}-\mathrm{CeO}_{2} @ \mathrm{CNF}$ for the HER, $4 \mathrm{mmol}$ of $\mathrm{Co}(\mathrm{acac})_{2} \cdot 4 \mathrm{H}_{2} \mathrm{O}$ and $4 \mathrm{mmol}$ of $\mathrm{Ce}\left(\mathrm{NO}_{3}\right)_{3} \cdot 6 \mathrm{H}_{2} \mathrm{O}$ were introduced into the PNA solution under rapid stirring for another $12 \mathrm{~h}$. The resultant solution was loaded into a syringe with a 22-gauge needle which was electrically connected to a high-voltage power supply. The applied potential between the needle and fiber collector (aluminum foil) was $27 \mathrm{kV}$. Then, the electrospinning was conducted with a flow rate of $1.5 \mathrm{~mL} / \mathrm{h}$. For the fabrication of the OER catalyst, $2 \mathrm{mmol}$ of $\mathrm{Ni}\left(\mathrm{NO}_{3}\right)_{2} \cdot 4 \mathrm{H}_{2} \mathrm{O}$ and $1 \mathrm{mmol}$ of $\mathrm{Fe}(\mathrm{acac})_{3} \cdot 6 \mathrm{H}_{2} \mathrm{O}$ were dissolved into the PAN solution under stirring at $500 \mathrm{rpm}$ for another $12 \mathrm{~h}$. The metal-precursor-dissolved solution was loaded into a syringe with a 27-gauge needle and electrospun with the flow rate of $0.8 \mathrm{~mL} / \mathrm{h}$ and applied voltage of $15 \mathrm{kV}$. The distance between the needle tip and fiber collector was $20 \mathrm{~cm}$. After the electrospinning, the collected fiber films were stabilized in air at $280{ }^{\circ} \mathrm{C}$ for $3 \mathrm{~h}$, then post thermal treatment was conducted at $900{ }^{\circ} \mathrm{C}$ for $5 \mathrm{~h}$ under a $\mathrm{N}_{2}$ atmosphere to obtain $\mathrm{Co}-\mathrm{CeO}_{2} @ \mathrm{CNF}$.

\subsection{Material Characterization}

To investigate the morphological properties of the as-fabricated electrocatalysts, scanning electron microscopy (SEM) and transmission electron microscopy (TEM) images were acquired using a JSM-7600F (Jeol Ltd., Tokyo, Japan) at the MEMS.Sensor Platform Center of Sungkyunkwan University (SKKU) and a JEM-2100F microscope (Jeol Ltd., Tokyo, Japan) operated at $200 \mathrm{kV}$, respectively. The crystalline properties of the sample powders were characterized by powder $\mathrm{X}$-ray diffraction 
(XRD). The obtained patterns were further investigated by using Joint Committee on Powder Diffraction Standards (JCPDS, v2.1, ICDD, Pennsylvania, USA) Card No. For XRD characterization, a D8-Advances (Bruker AXS, Karlsruhe, Germany) diffractometer with a $\mathrm{Cu} \mathrm{K} \alpha$ radiation source $(\lambda=0.15418 \mathrm{~nm})$ was used. X-ray photo-electron spectroscopy (XPS) was performed using an ESCA2000 (VG Microtech, East Grinstead, UK).

\subsection{Electrochemical Measurements}

For the fabrication of the electrodes, we prepared Ketjen black as a conductive agent, polyvinylidene fluoride as a binder and a mixture of a catalyst in a weight ratio of 20:10:70. These components were dissolved in N-methyl-2-pyrrolidone. Then, the sample slurry was coated onto a carbon paper substrate $\left(1 \times 1 \mathrm{~cm}^{2}\right)$ and a vacuum dry was conducted overnight at $80^{\circ} \mathrm{C}$. Polarization and cyclic voltammetry $(\mathrm{CV})$ curves were obtained using a CHI600D electrochemical analyzer (CH instrument) in a 1-M KOH solution. For the three-electrode configuration, $\mathrm{Hg} / \mathrm{HgO}$ and $\mathrm{Pt}$ wire were used as reference and counter electrodes, respectively. Chrono-potentiometric curves were obtained using a WBCS-3000 (Xeno Co.) in a 1-M KOH solution. Electrochemical impedance spectroscopy (EIS) measurements were performed at $-1.1 \mathrm{~V}$ versus a reversible hydrogen electrode (RHE) (alternating-current excitation signal) in a frequency range of $100 \mathrm{kHz}$ to $0.1 \mathrm{~Hz}$. All potential values were converted to the RHE scale by using $E_{\mathrm{RHE}}=E_{\mathrm{SCE}}+E_{\mathrm{SCE}}^{0}+0.059 \times \mathrm{pH}$, where $E_{\mathrm{SCE}}$ is the potential measured using a saturated calomel electrode (SCE) reference, and $E^{0} \mathrm{SCE}$ is the standard potential of the SCE at $25^{\circ} \mathrm{C}(0.078 \mathrm{~V})$, unless otherwise stated.

\section{Results}

The $\mathrm{Co}-\mathrm{CeO}_{2} @ \mathrm{CNF}$ catalyst was fabricated by electrospinning and pyrolysis. A PAN solution containing metal precursors was electrospun on an aluminum current collector under an applied bias. The obtained polymer mat was transformed into a black $\mathrm{Co}-\mathrm{CeO}_{2} @ \mathrm{CNF}$ catalyst upon thermal treatment at $900{ }^{\circ} \mathrm{C}$ for $5 \mathrm{~h}$ in a tubular furnace under a $\mathrm{N}_{2}$ atmosphere. Figure 1a shows a typical SEM image of the synthesized $\mathrm{Co}-\mathrm{CeO}_{2} @ \mathrm{CNF}$. A SEM image of a pristine CNF is shown in Figure S1 (Supplementary Information). The obtained nanofiber exhibited a one-dimensional structure with a diameter of approximately $840 \mathrm{~nm}$. The higher-magnification SEM image shows that the surface of $\mathrm{Co}-\mathrm{CeO}_{2} @ \mathrm{CNF}$ was coarse, with numerous $\mathrm{Co}-\mathrm{CeO}_{2}$ nanoparticles homogeneously dispersed in the nanofiber support (Figure $1 \mathrm{~b}$ ). The TEM image demonstrates the successful formation of $\mathrm{Co}-\mathrm{CeO}_{2}$ nanoparticles on the surface of the CNF (Figure 1c). Co, Ce, C, N, and O elements were uniformly distributed in the CNF. An energy-dispersive X-ray spectroscopy (EDS) analysis shows an atomic ratio of Co:Ce of approximately 1:1 (Figure 1d,e, and Figure S2 in Supplementary Information). The XRD pattern of $\mathrm{Co}-\mathrm{CeO}_{2} @ \mathrm{CNF}$ shows three high peaks at $44.2^{\circ}, 51.5^{\circ}$, and $75.8^{\circ}$ corresponding to the (111), (200), and (220) planes of Co metal with a face-centered cubic (FCC) structure (JCPDS\# 15-0806) respectively (Figure 1f). The formation of the $\mathrm{FCC} \mathrm{CeO}_{2}$ (JCPDS\# 81-0792) was confirmed by the diffraction peaks at $28.4,32.9,47.4,56.3,59.0,69.4,76.6$, and $79.0^{\circ}$ corresponding to the (111), (200), (220), (311), (222), (400), (331), and (420) planes, respectively. These results indicate that metal and oxide nanoparticles were formed in the CNF by electrospinning and pyrolysis. To understand the roles of the metal cations in the synthesis of $\mathrm{Co}-\mathrm{CeO}_{2} @ \mathrm{CNF}$, bare $\mathrm{Co} @ \mathrm{CNF}$ and $\mathrm{CeO}_{2} @ \mathrm{CNF}$ were synthesized by the same processes used for the synthesis of $\mathrm{Co}-\mathrm{CeO}_{2} @ \mathrm{CNF}$ but without the Co or Ce precursors. When the synthesis was performed without $\mathrm{Ce}\left(\mathrm{NO}_{3}\right)_{3}$ (the other conditions were identical to those for the sample in Figure S3a (Supplementary Information)), Co nanocrystals with a cubic structure were formed; this was confirmed by XRD (JCPDS Card No. 81-0792, Figure S3b in Supplementary Information). Without the $\mathrm{Co}(\mathrm{acac})_{2}$ precursor, $\mathrm{CeO}_{2}$ microparticles with a low-crystallinity cubic phase were obtained as the product (Figure S3c,d in Supplementary Information). These results indicate that both $\mathrm{Co}$ and $\mathrm{Ce}$ cations favored the formation of $\mathrm{Co}-\mathrm{CeO}_{2}$ nanoparticles. Figure $1 \mathrm{~g}-\mathrm{i}$ depicts the $\mathrm{XP}$ spectra of Co $2 p, \mathrm{Ce} 3 d$, and $\mathrm{O} 1$ s respectively. The Co $2 p$ core-level spectrum exhibited peaks at $780.5,782.8,785.0$, and $787.0 \mathrm{eV}$, which were assigned as $\mathrm{Co} 2 p_{3 / 2} \mathrm{Co}^{3+}, \mathrm{Co} 2 p_{3 / 2} \mathrm{Co}^{2+}$, and satellite 
peaks, respectively. The peaks centered at 796.1 and $798.5 \mathrm{eV}$ correspond to $\mathrm{Co} 2 p_{1 / 2} \mathrm{Co}^{3+}$ and Co $2 p_{1 / 2}$ $\mathrm{Co}^{2+}$ respectively [31]. The Ce $3 d$ core-level spectrum contained peaks associated with both $\mathrm{Ce}^{3+}$ and $\mathrm{Ce}^{4+}$ [32]. The electrons in the $4 f^{1}$ orbital of $\mathrm{Ce}^{3+}$ could considerably influence the interaction between the ceria and the surrounding Co nanoparticles. Moreover, oxygen vacancies can be induced by the charge compensation of $\mathrm{Ce}^{3+}$ ions on the surface of $\mathrm{CeO}_{2}[1,31]$. This can enhance the electrochemical water-splitting catalytic kinetics of the $\mathrm{Co}-\mathrm{CeO}_{2}$-incorporated CNF.

a

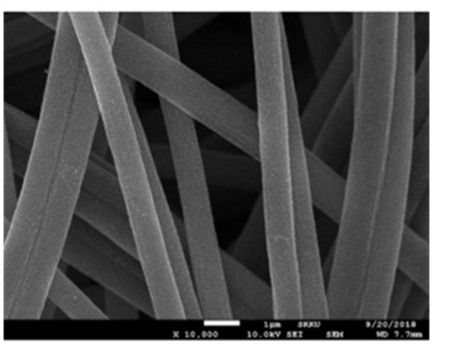

d

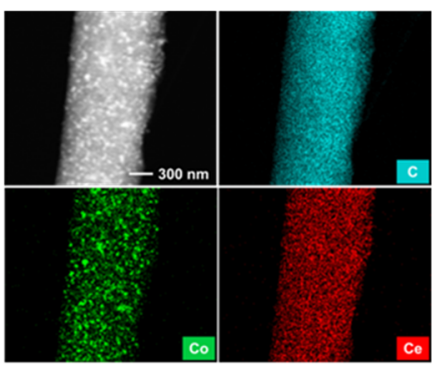

g

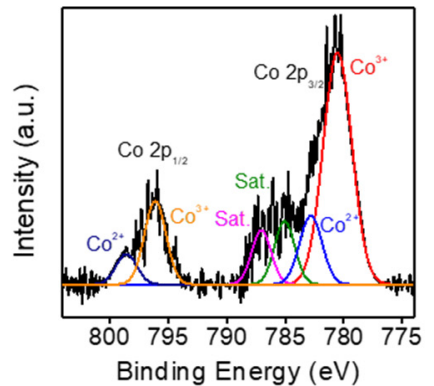

b
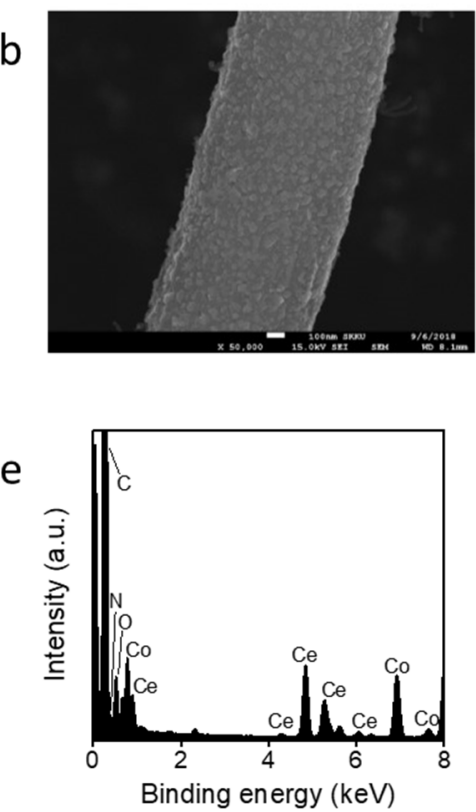

$\mathrm{h}$

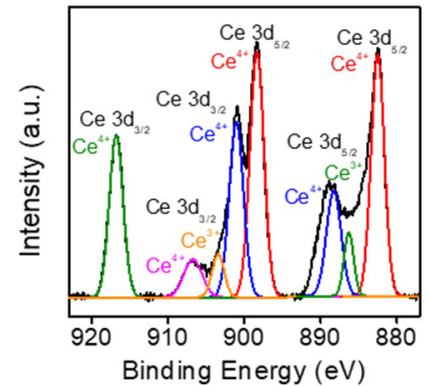

$\mathrm{C}$
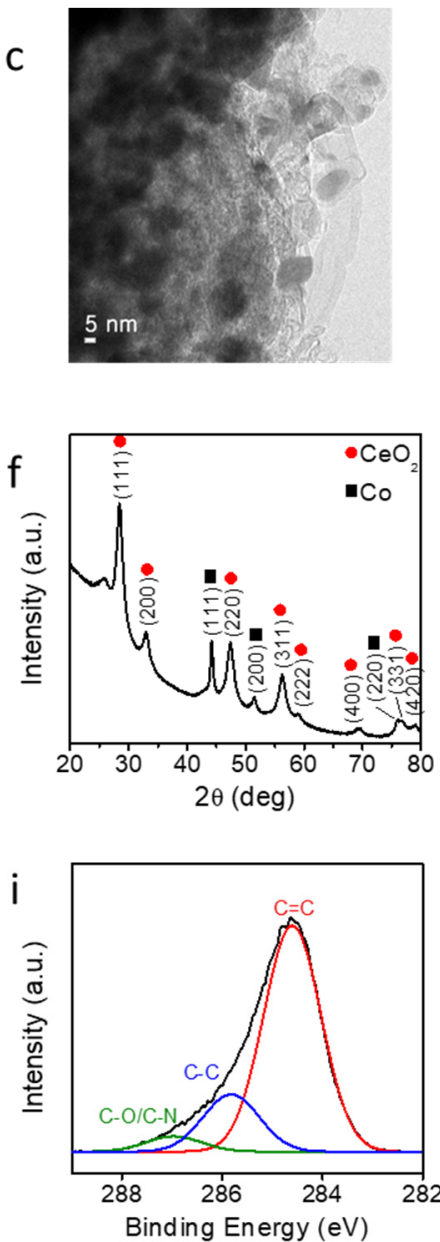

Figure 1. Characterization of $\mathrm{Co}_{-}-\mathrm{CeO}_{2} @ \mathrm{CNF}$. (a,b) SEM and (c) TEM images, (d) scanning TEM image and EDS elemental maps, (e) EDS data, (f) XRD pattern, and (g-i) XPS analysis of $\mathrm{Co}-\mathrm{CeO}_{2} @ \mathrm{CNF}$.

We investigated the effects of the electrochemical catalytic properties of $\mathrm{Co}_{-}-\mathrm{CeO}_{2} @ \mathrm{CNF}$ on the HER and compared them with those of $\mathrm{Co@CNF}, \mathrm{CeO}_{2} @ \mathrm{CNF}, \mathrm{CNF}$, commercial Pt/C, and carbon paper electrodes. Figure 2a shows polarization curves for the HERs, including the bare carbon paper. The $\mathrm{Co}-\mathrm{CeO}_{2} @ \mathrm{CNF}$ electrode exhibited a significant overpotential of $92 \mathrm{mV}$ at a current density of -10 $\mathrm{mA} / \mathrm{cm}^{2}$ with the $i R$ compensation; the corresponding values for the $\mathrm{Co} @ \mathrm{CNF}, \mathrm{CeO}_{2} @ \mathrm{CNF}$, and bare CNF electrodes were 270, 381, and $506 \mathrm{mV}$, respectively, while that for the $\mathrm{Pt} / \mathrm{C}$ electrode was $54 \mathrm{mV}$ (Figure 2b). This value was also lower than previously reported $\mathrm{Co}$ and $\mathrm{CeO}_{2}$ based catalysts (Table S1). The Tafel slope of the $\mathrm{Co}-\mathrm{CeO}_{2} @ \mathrm{CNF}$ electrode was $54 \mathrm{mV} / \mathrm{dec}$, considerably smaller than those of the Co@CNF (118 mV/dec), $\mathrm{CeO}_{2} @ \mathrm{CNF}$ (154 mV/dec), and CNF (146 mV/dec) electrodes (Figure 2c). It was slightly larger than that of the $\mathrm{Pt} / \mathrm{C}$ electrode $(31 \mathrm{mV} / \mathrm{dec})$ [33]. Figure $2 \mathrm{~d}$ shows Nyquist plots obtained from an EIS measurement. Consistently with the HER activities, the charge-transfer resistance $\left(R_{\mathrm{ct}}\right)$ of the $\mathrm{Co}-\mathrm{CeO}_{2} @ \mathrm{CNF}$ electrode was considerably smaller than those of the Co@CNF and $\mathrm{CeO}_{2} @ \mathrm{CNF}$ electrodes. This is consistent with the low overpotential and high HER activity of $\mathrm{Co}-\mathrm{CeO}_{2} @ \mathrm{CNF}$. Furthermore, the electrochemical active surface area was characterized by investigating 
the electrochemical double-layer capacitance $\left(C_{\mathrm{dl}}\right)$ via $\mathrm{CV}$ (Figure $\mathrm{S} 4$ in Supplementary Information). The estimated $C_{\mathrm{dl}}$ of the $\mathrm{Co}-\mathrm{CeO}_{2} @ \mathrm{CNF}$ electrode was $154.3 \mathrm{mF} / \mathrm{cm}^{2}$, whereas those of the Co@CNF and $\mathrm{CeO}_{2} @ \mathrm{CNF}$ electrodes were 58.7 and $85.6 \mathrm{mF} / \mathrm{cm}^{2}$, respectively (Figure 2e). The higher capacitance of $\mathrm{Co}-\mathrm{CeO}_{2} @ \mathrm{CNF}$ than that of $\mathrm{Co} @ \mathrm{CNF}$ and $\mathrm{CeO}_{2} @ \mathrm{CNF}$ indicates that its unique porous structure and effective active sites contributed to its high HER performance. To investigate the long-term durability of $\mathrm{Co}-\mathrm{CeO}_{2} @ \mathrm{CNF}$, its overpotential at the current density of $-10 \mathrm{~mA} / \mathrm{cm}^{2}$ was monitored over time without iR compensation (Figure 2f). Notably, no significant change in overpotential (159.3-166.1 mV) was observed over the $70 \mathrm{~h}$ of operation.
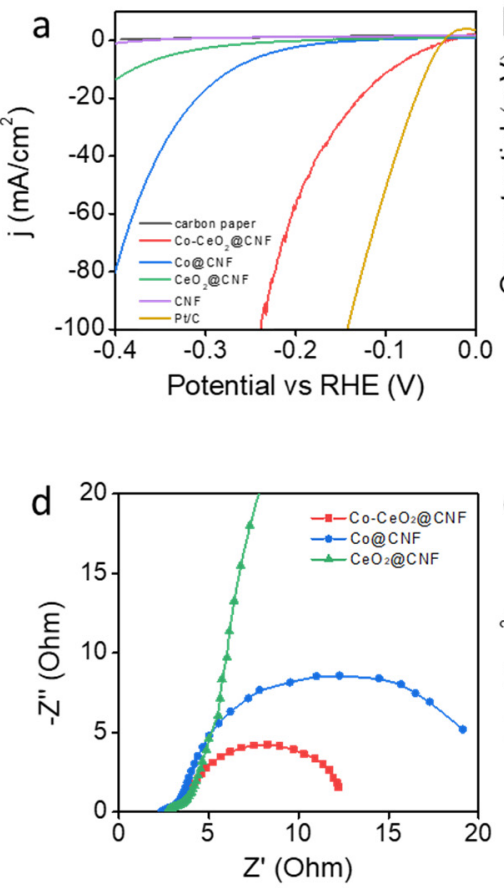
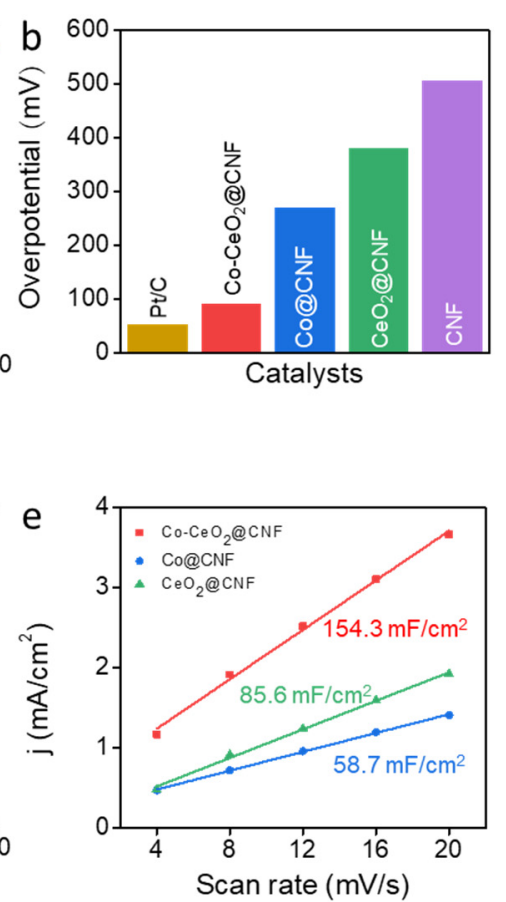
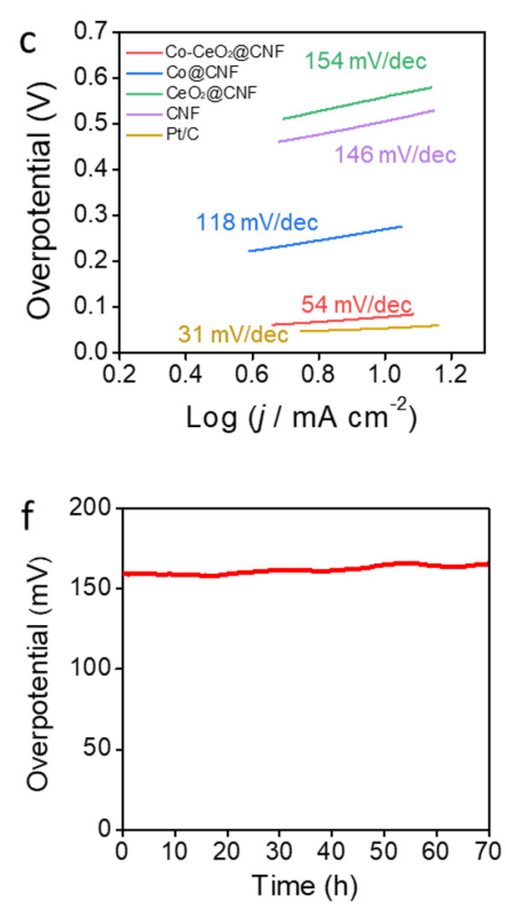

Figure 2. Electrochemical performances of the electrocatalysts for the HER in 1-M KOH. (a) HER polarization curves of the $\mathrm{Co}-\mathrm{CeO}_{2} @ \mathrm{CNF}, \mathrm{Co} @ \mathrm{CNF}, \mathrm{CeO}_{2} @ \mathrm{CNF}, \mathrm{CNF}$, commercial Pt/C, and bare carbon paper electrodes recorded in the 1-M KOH solution at a scan rate of $1 \mathrm{mV} / \mathrm{s}$ from negative to positive potentials at room temperature. (b) Comparison of the HER overpotentials of the $\mathrm{Co}-\mathrm{CeO}_{2} @ \mathrm{CNF}$, Co@CNF, $\mathrm{CeO}_{2} @ \mathrm{CNF}, \mathrm{CNF}$, and commercial Pt/C electrodes in the 1-M KOH. (c) Tafel plots of the Co-CeO $\mathrm{C}_{2} @ \mathrm{CNF}, \mathrm{Co} @ \mathrm{CNF}, \mathrm{CeO}_{2} @ \mathrm{CNF}, \mathrm{CNF}$, and commercial Pt/C electrodes for the HER. (d) EIS plots of the $\mathrm{Co}-\mathrm{CeO}_{2} @ \mathrm{CNF}, \mathrm{Co} @ \mathrm{CNF}$, and $\mathrm{CeO}_{2} @ \mathrm{CNF}$ electrodes at an applied potential of $-0.2 \mathrm{~V}$ vs. RHE. (e) Electrochemical active surface areas of the $\mathrm{Co}-\mathrm{CeO}_{2} @ \mathrm{CNF}, \mathrm{Co} @ \mathrm{CNF}$, and $\mathrm{CeO}_{2} @ \mathrm{CNF}$ electrodes obtained by using the double-layer capacitances. (f) $i R$-uncorrected chronopotentiometry curve of the $\mathrm{Co}-\mathrm{CeO}_{2} @ \mathrm{CNF}$ electrode at a constant current density of $-10 \mathrm{~mA} / \mathrm{cm}^{2}$ over a period of $70 \mathrm{~h}$.

For the counterpart, water electrolysis, $\mathrm{Ni}_{2} \mathrm{Fe} @ \mathrm{CNF}$ was used for the fabrication of the OER electrode by the same synthesis process as was used for $\mathrm{Co}-\mathrm{CeO}_{2} @ \mathrm{CNF}$. The surface morphology of $\mathrm{Ni}_{2} \mathrm{Fe} @ \mathrm{CNF}$ was observed using SEM, as shown in Figure 3a. The resulting nanofibers had an average diameter of approximately $610 \mathrm{~nm}$ and an average particle size below $100 \mathrm{~nm}$. The nanoparticles were encapsulated and well-embedded in the CNF. The EDS elemental maps in Figure 3b and Figure S5 in Supplementary Information show that $\mathrm{Ni}, \mathrm{Fe}, \mathrm{C}, \mathrm{N}$, and $\mathrm{O}$ elements were uniformly distributed in the CNFs. The XRD pattern of $\mathrm{Ni}_{2} \mathrm{Fe} @ \mathrm{CNF}$ shows diffraction peaks centered at $2 \theta$ values of $43.8^{\circ}, 51.2^{\circ}$, and $75.3^{\circ}$, corresponding to (111), (200), and (220) reflections, respectively (Figure 3c). These results indicate that $\mathrm{Ni}_{2} \mathrm{Fe}$ metal nanoparticles were successfully formed in the CNF through electrospinning and pyrolysis. The Ni $2 p$ core-level XP spectrum contained peaks associated with both $\mathrm{Ni}^{2+}(854.3$ and $871.3 \mathrm{eV})$ and $\mathrm{Ni}^{3+}(856.0$ and $873.2 \mathrm{eV})$. The Fe $2 p$ core-level XP spectrum exhibited peaks corresponding to both $\mathrm{Fe}(707.1 \mathrm{eV})$ and $\mathrm{Fe}^{3+}$ (710.4 eV) (Figure 3d). Further, we evaluated the 
electrocatalytic performance of $\mathrm{Ni}_{2} \mathrm{Fe} @ \mathrm{CNF}$ for the OER and compared its performance with those of commercially utilized $\mathrm{IrO}_{2}$ nanoparticles with sizes of 30-150 nm and the control catalysts Ni@CNF, Fe@CNF, and bare CNF [33]. Figure 3e shows the OER polarization curves of five catalysts, including the commercial $\mathrm{IrO}_{2}$. With the $i R$ compensation, the overpotential of the $\mathrm{Ni}_{2} \mathrm{Fe} @ \mathrm{CNF}$ electrode was $242 \mathrm{mV}$ at a current density of $10 \mathrm{~mA} / \mathrm{cm}^{2}$. The overpotentials of the Ni@CNF, Fe@CNF, CNF, and commercialized $\mathrm{IrO}_{2}$ catalysts were 478, 355, 561, and $284 \mathrm{mV}$, respectively. This OER performance was also similar or lower than that for previously reported Ni and Fe based catalysts (Table S2). The Tafel plot in Figure $3 \mathrm{f}$ shows the kinetics of the electrochemical OER on each catalyst. The Tafel slope of the $\mathrm{Ni}_{2} \mathrm{Fe} @ \mathrm{CNF}$ electrode was $81 \mathrm{mV} / \mathrm{dec}$, considerably smaller than that of the Ni@CNF (248 mV/dec), Fe@CNF (109 mV/dec), and $\mathrm{IrO}_{2} / \mathrm{NF}(121 \mathrm{mV} / \mathrm{dec})$ electrodes. The significantly low overpotential and small Tafel slope of $\mathrm{Ni}_{2} \mathrm{Fe} @ \mathrm{CNF}$ indicate its high OER efficiency. The Nyquist plots obtained from the EIS measurement reveal the charge-transfer resistances $\left(R_{\mathrm{ct}}\right)$ during the electrochemical catalytic reactions of the $\mathrm{Ni}_{2} \mathrm{Fe} @ \mathrm{CNF}, \mathrm{Ni} @ \mathrm{CNF}$, and Fe@CNF electrodes. As shown in Figure $3 \mathrm{~g}$, the $\mathrm{Ni}_{2} \mathrm{Fe} @ \mathrm{CNF}$ electrode exhibited a considerably smaller $R_{\mathrm{ct}}$ of $36.5 \Omega$ than the Ni@CNF (475.4 $\Omega$ ) and Fe@CNF $\left(77.0 \Omega\right.$ ) electrodes did. The small $R_{\mathrm{ct}}$ reflects the favorable charge migration and desirable catalytic kinetics which led to the small Tafel slope. Moreover, the conformally embedded $\mathrm{Ni}_{2} \mathrm{Fe}$ nanoparticles in the CNF provided efficient electrical contacts and chemical stability of the composite, which also contributed to the superior stability [34]. To evaluate the long-term stabilities of the $\mathrm{Ni}_{2} \mathrm{Fe} @ \mathrm{CNF}$ electrode at large current densities, the overpotential for the OER was monitored at a constant current density of $50 \mathrm{~mA} / \mathrm{cm}^{2}$ for $70 \mathrm{~h}$. As shown in Figure 3h, no significant change in the potential required to maintain the current density of $50 \mathrm{~mA} / \mathrm{cm}^{2}$ was observed in the period of $70 \mathrm{~h}$. This demonstrates the excellent catalytic stability of the $\mathrm{Ni}_{2} \mathrm{Fe} @ \mathrm{CNF}$ electrode for the OER.

a
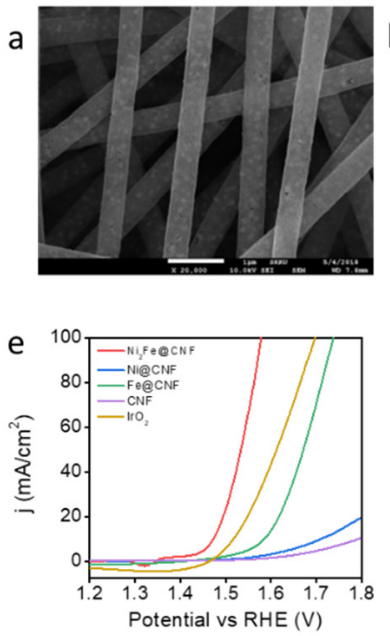
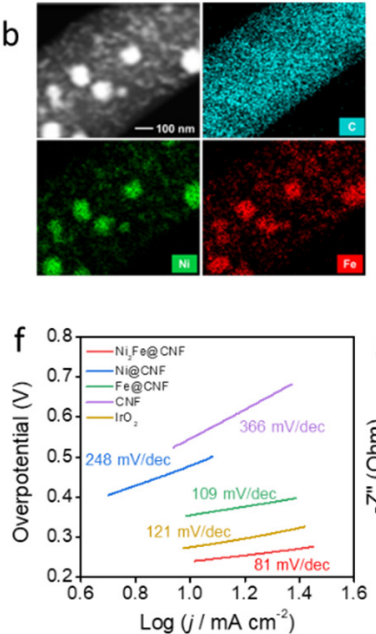
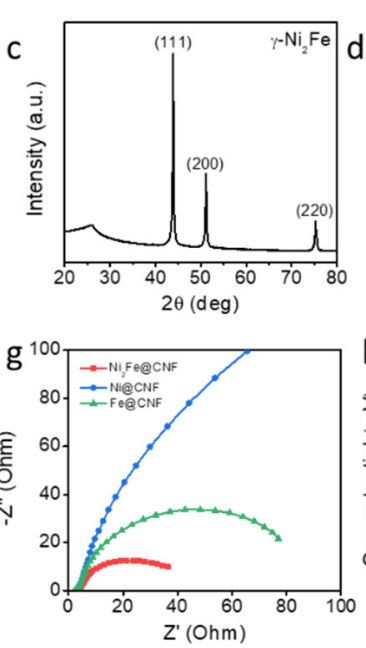
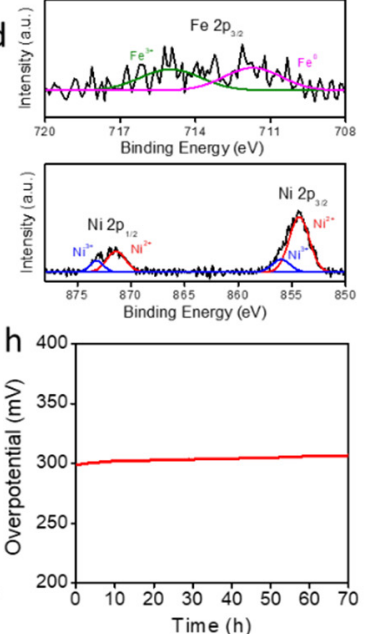

Figure 3. $\mathrm{Ni}_{2} \mathrm{Fe} @ \mathrm{CNF}$ for the OER electrode. (a) SEM images, (b) EDS elemental maps, (c) XRD pattern, and (d) XPS analysis of $\mathrm{Ni}_{2} \mathrm{Fe} @ \mathrm{CNF}$. (e) Polarization curves of the $\mathrm{Ni}_{2} \mathrm{Fe} @ \mathrm{CNF}, \mathrm{Ni} \mathrm{CNF}$, $\mathrm{Fe} @ \mathrm{CNF}, \mathrm{CNF}$, commercial $\mathrm{IrO}_{2}$, and bare carbon paper electrodes recorded in a 1-M KOH solution at a scan rate of $1 \mathrm{mV} / \mathrm{s}$ from negative to positive potentials at room temperature. (f) Tafel plots of the $\mathrm{Ni}_{2} \mathrm{Fe} @ \mathrm{CNF}$, Ni@CNF, Fe@CNF, CNF, and commercial $\mathrm{IrO}_{2}$ electrodes for the OER. (g) EIS plots of the $\mathrm{Ni}_{2} \mathrm{Fe} @ \mathrm{CNF}, \mathrm{Co} @ \mathrm{CNF}$, and $\mathrm{CeO}_{2} @ \mathrm{CNF}$ electrodes at an applied potential of $1.53 \mathrm{~V}$ vs. RHE. (h) Chrono-potentiometry curve of the $\mathrm{Ni}_{2} \mathrm{Fe} @ \mathrm{CNF}$ electrode at a constant current density of $50 \mathrm{~mA} / \mathrm{cm}^{2}$ over a period of $70 \mathrm{~h}$.

For overall water splitting, we paired the $\mathrm{Co}-\mathrm{CeO}_{2} @ \mathrm{CNF} \mathrm{HER}$ electrocatalyst with the high-performance (Figure S6 in Supplementary Information) $\mathrm{Ni}_{2} \mathrm{Fe} @$ CNF OER electrocatalyst (Figure S7 in Supplementary Information) in a 1-M KOH, to obtain an alkaline electrolyzer (Figure 4a). For the comparison, an electrolyzer was fabricated by pairing the $\mathrm{Pt} / \mathrm{C}$ and $\mathrm{IrO}_{2}$ electrodes (Figure $4 \mathrm{~b}$ ). In the electrolyzer based on the $\mathrm{Co}-\mathrm{CeO}_{2} @ \mathrm{CNF}$ and $\mathrm{Ni}_{2}$ Fe@CNF electrodes, an overall-water-splitting current 
density of $10 \mathrm{~mA} / \mathrm{cm}^{2}$ was achieved by applying only $1.587 \mathrm{~V}$ across the electrodes with $i R$ compensation. The lower overpotential of $257 \mathrm{mV}$ was observed when that of the electrolyzer based on the $\mathrm{Pt} / \mathrm{C}$ and $\mathrm{IrO}_{2}$ electrodes was $400 \mathrm{mV}$. In Figure $4 \mathrm{c}$, the stability of the $\mathrm{Co}-\mathrm{CeO}_{2} @ \mathrm{CNF}$ and $\mathrm{Ni}_{2} \mathrm{Fe} @ \mathrm{CNF}$ electrodes was investigated by monitoring the applied potential values at a constant water-splitting current density of $10 \mathrm{~mA} / \mathrm{cm}^{2}$. As shown in Figure 4c, the performance of the $\mathrm{Co}-\mathrm{CeO}_{2} @ \mathrm{CNF}$ and $\mathrm{Ni}_{2} \mathrm{Fe} @ \mathrm{CNF}$ electrodes was maintained over $70 \mathrm{~h}$ of chrono-potentiometry testing.
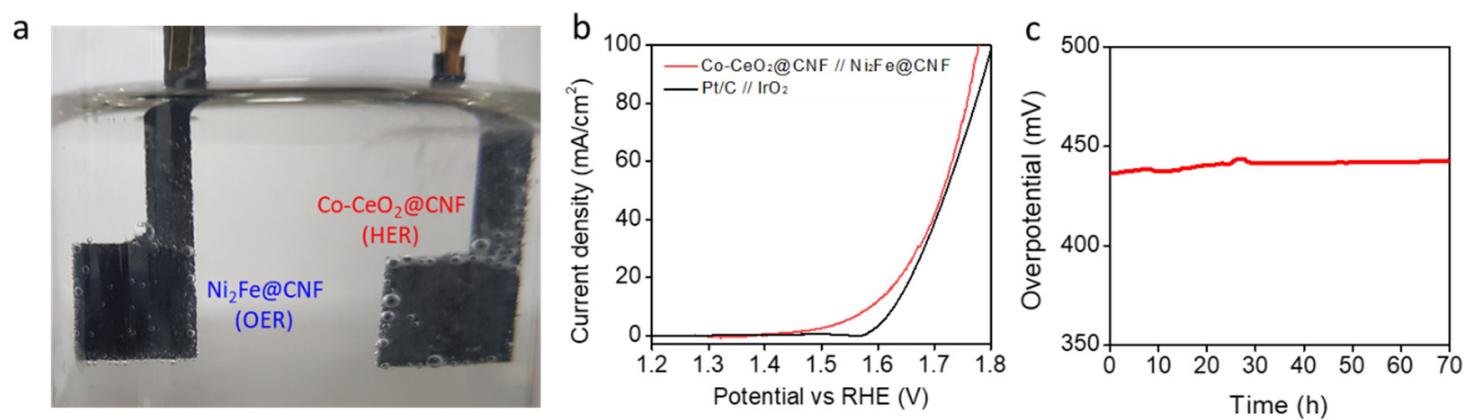

Figure 4. Electrochemical performances of the electrolyzer with $\mathrm{Co}-\mathrm{CeO}_{2} @ \mathrm{CNF} / / \mathrm{Ni} 2 \mathrm{Fe} @ \mathrm{CNF}$ for overall water splitting. (a) Optical image of the $\mathrm{Co}-\mathrm{CeO}_{2} @ / / \mathrm{Ni}_{2} \mathrm{Fe} @ \mathrm{CNF}$ electrolyzer. (b) Overall water splitting characteristics of the $\mathrm{Co}-\mathrm{CeO}_{2} @ \mathrm{CNF} / / \mathrm{Ni}_{2} \mathrm{Fe} @ \mathrm{CNF}$ and $\mathrm{IrO}_{2} / /(\mathrm{Pt} / \mathrm{C})$ electrolyzers measured in a two-electrode configuration in the range of 1.8 to $1.2 \mathrm{~V}$ at a scan rate of $1 \mathrm{mV} / \mathrm{s}$ in a 1-M KOH solution. (c) $i R$-uncorrected chrono-potentiometric curve of the $\mathrm{Co}-\mathrm{CeO}_{2} @ \mathrm{CNF} / / \mathrm{Ni}_{2} \mathrm{Fe} @ \mathrm{CNF}$ electrolyzer at a steady-state current density of $10 \mathrm{~mA} / \mathrm{cm}^{2}$ in a $1-\mathrm{M} \mathrm{KOH}$ solution.

\section{Conclusions}

Simple electrospinning combined with pyrolysis were utilized to fabricate transition-metal-incorporated CNF electrocatalysts to achieve efficient overall water splitting. For the $\mathrm{HER}, \mathrm{Co}-\mathrm{CeO}_{2}$ nanoparticles with an $\mathrm{Co}$ Ce atomic ratio of approximately 1:1 were homogeneously dispersed on CNF supports $\left(\mathrm{Co}-\mathrm{CeO}_{2} @ \mathrm{CNF}\right)$. Co-CeO $\mathrm{C}_{2} \mathrm{CNF}$ exhibited an outstanding electrocatalytic performance for the HER. Its overpotential and Tafel slope were $92 \mathrm{mV}$ at a current density of $-10 \mathrm{~mA} / \mathrm{cm}^{2}$ and $54 \mathrm{mV} / \mathrm{dec}$ respectively. $\mathrm{Ni}_{2} \mathrm{Fe} @ \mathrm{CNF}$ was fabricated for the counterpart, water electrolysis. With the $i R$ compensation, the overpotential of the $\mathrm{Ni}_{2} \mathrm{Fe} @ \mathrm{CNF}$ electrode was $242 \mathrm{mV}$ at a current density of $10 \mathrm{~mA} / \mathrm{cm}^{2}$. The Tafel slope of the $\mathrm{Ni}_{2} \mathrm{Fe} @ \mathrm{CNF}$ electrode was $81 \mathrm{mV} / \mathrm{dec}$, considerably smaller than that of the commercialized $\mathrm{IrO}_{2} / \mathrm{NF}$ electrode $(121 \mathrm{mV} / \mathrm{dec})$. To evaluate their electrochemical properties for the overall water splitting, $\mathrm{Co}-\mathrm{CeO}_{2} @ \mathrm{CNF}$ and $\mathrm{Ni}_{2} \mathrm{Fe} @ \mathrm{CNF}$ were used as the HER and OER electrocatalysts in an alkaline electrolyzer, respectively. Their performances were compared with that of an electrolyzer fabricated by pairing $\mathrm{Pt} / \mathrm{C}$ and $\mathrm{IrO} 2$ electrodes. With the paired $\mathrm{Co}-\mathrm{CeO}_{2} @ \mathrm{CNF}$ and $\mathrm{Ni}_{2} \mathrm{Fe} @ \mathrm{CNF}$ electrodes, an overall water splitting current density of $10 \mathrm{~mA} / \mathrm{cm}^{2}$ was achieved by applying $1.587 \mathrm{~V}$ across the electrodes. The significantly lower overpotential of $257 \mathrm{mV}$ was achieved when the overpotential of electrolyzer based on the $\mathrm{Pt} / \mathrm{C}$ and $\mathrm{IrO}_{2}$ electrodes was $400 \mathrm{mV}$. Owing to the conformal incorporation of nanoparticles into the CNF supports, the electrocatalysts exhibited significant long-term durability. The performance of the Co- $\mathrm{CeO}_{2} @ \mathrm{CNF}$ and $\mathrm{Ni}_{2} \mathrm{Fe} @ \mathrm{CNF}$ electrodes was maintained over 70 h of operation.

Supplementary Materials: The supplementary materials are available online at http://www.mdpi.com/1996-1944/ 13/4/856/s1, Figure S1: SEM images of the pristine CNF fabricated via electrospinning and pyrolysis, Figure S2: EDS elemental mapping TEM images of the $\mathrm{Co}-\mathrm{CeO}_{2} @ C N F$ representing as (a) O and (b) N, Figure S3: SEM images and XRD patterns of $(a, b) \mathrm{Co@CNF}$ and $(c, d) \mathrm{CeO}_{2} @ C N F$, respectively, Figure S4: CV curves of (a)Co-CeO2@CNF, (b)Co@CNF, and (c)CeO2@CNF at various scan rates, Figure S5: EDS elemental mapping TEM images of the Ni2Fe@CNF representing as (a) $\mathrm{O}$ and (b) N, Figure S6: Polarization curves of $\mathrm{Co}-\mathrm{CeO}_{2} @ \mathrm{CNF}$ at various amount of $\mathrm{Co}-\mathrm{CeO}_{2}$, Figure S7: Polarization curves of $\mathrm{Ni}_{2} \mathrm{Fe} @ \mathrm{CNF}$ at various amount of $\mathrm{Ni}_{2} \mathrm{Fe}$, Table S1: HER performance compared to previously reported catalysts, Table S2: OER performance compared to previously reported catalysts.

Author Contributions: B.L. conceived of the idea; B.L. and J.K.K. supervised the research; S.W. synthesized samples, characterization and estimated electrochemical performances; J.L. analyzed the data and optimized the 
system; D.S.L. took the images with microscopy; S.W., J.K.K., and B.L. wrote the first draft of the manuscript, and all authors contributed to the revision the manuscript. All authors have read and agreed to the published version of the manuscript.

Funding: This work was supported by the Basic Science Research Program through the National Research Foundation (NRF) of Korea funded by the Ministry of Science, ICT, and Future Planning (2019R1A2C2006997), and the Korea Basic Science Institute (KBSI) National Research Facilities \& Equipment Center (NFEC) grant funded by the Korea government (Ministry of Education) (2019R1A6C1010031). This study has been conducted with the support of the Korea Institute of Industrial Technology as "Development of smart textronic products based on electronic fibers and textiles (kitech JA-19-0001)" and the Gyeongi-Do Technology Development Program as "Development of smart textronic products based on electronic fibers and textiles (kitech IZ-19-0003)".

Conflicts of Interest: The authors declare no conflict of interest.

\section{References}

1. Dong, H.; Liu, C.; Ye, H.; Hu, L.; Fugetsu, B.; Dai, W.; Cao, Y.; Qi, X.; Lu, H.; Zhang, X. Three-dimensional nitrogen-doped graphene supported molybdenum disulfide nanoparticles as an advanced catalyst for hydrogen evolution reaction. Sci. Rep. 2015, 5, 17542. [CrossRef] [PubMed]

2. Anantharaj, S.; Ede, S.R.; Karthick, K.; Sam Sankar, S.; Sangeetha, K.; Karthik, P.E.; Kundu, S. Precision and correctness in the evaluation of electrocatalytic water splitting: Revisiting activity parameters with a critical assessment. Energy Environ. Sci. 2018, 11, 744-771. [CrossRef]

3. Yan, D.; Chen, R.; Xiao, Z.; Wang, S. Engineering the electronic structure of $\mathrm{CO}_{3} \mathrm{O}_{4}$ by carbon-doping for efficient overall water splitting. Electrochim. Acta 2019, 303, 316-322. [CrossRef]

4. Ma, Y.-Y.; Wu, C.-X.; Feng, X.-J.; Tan, H.-Q.; Yan, L.-K.; Liu, Y.; Kang, Z.-H.; Wang, E.-B.; Li, Y.-G. Highly efficient hydrogen evolution from seawater by a low-cost and stable comop@c electrocatalyst superior to pt/c. Energy Environ. Sci. 2017, 10, 788-798. [CrossRef]

5. Lu, Q.; Hutchings, G.S.; Yu, W.; Zhou, Y.; Forest, R.V.; Tao, R.; Rosen, J.; Yonemoto, B.T.; Cao, Z.; Zheng, H.; et al. Highly porous non-precious bimetallic electrocatalysts for efficient hydrogen evolution. Nat. Commun. 2015, 6, 6567. [CrossRef]

6. Deng, J.; Ren, P.; Deng, D.; Bao, X. Enhanced electron penetration through an ultrathin graphene layer for highly efficient catalysis of the hydrogen evolution reaction. Angew. Chem. Int. Ed. 2015, 54, 2100-2104. [CrossRef]

7. Zhang, H.; Ma, Z.; Duan, J.; Liu, H.; Liu, G.; Wang, T.; Chang, K.; Li, M.; Shi, L.; Meng, X.; et al. Active sites implanted carbon cages in core-shell architecture: Highly active and durable electrocatalyst for hydrogen evolution reaction. ACS Nano 2016, 10, 684-694. [CrossRef]

8. Wu, H.B.; Xia, B.Y.; Yu, L.; Yu, X.-Y.; Lou, X.W. Porous molybdenum carbide nano-octahedrons synthesized via confined carburization in metal-organic frameworks for efficient hydrogen production. Nat. Commun. 2015, 6, 6512. [CrossRef]

9. Li, J.-S.; Wang, Y.; Liu, C.-H.; Li, S.-L.; Wang, Y.-G.; Dong, L.-Z.; Dai, Z.-H.; Li, Y.-F.; Lan, Y.-Q. Coupled molybdenum carbide and reduced graphene oxide electrocatalysts for efficient hydrogen evolution. Nat. Commun. 2016, 7, 11204. [CrossRef] [PubMed]

10. Xie, J.; Li, S.; Zhang, X.; Zhang, J.; Wang, R.; Zhang, H.; Pan, B.; Xie, Y. Atomically-thin molybdenum nitride nanosheets with exposed active surface sites for efficient hydrogen evolution. Chem. Sci. 2014, 5, 4615-4620. [CrossRef]

11. An, T.-Y.; Surendran, S.; Kim, H.; Choe, W.-S.; Kim, J.K.; Sim, U. A polydopamine-mediated biomimetic facile synthesis of molybdenum carbide-phosphide nanodots encapsulated in carbon shell for electrochemical hydrogen evolution reaction with long-term durability. Comp. B Eng. 2019, 175, 107071. [CrossRef]

12. Jin, Y.; Wang, H.; Li, J.; Yue, X.; Han, Y.; Shen, P.K.; Cui, Y. Porous $\mathrm{moO}_{2}$ nanosheets as non-noble bifunctional electrocatalysts for overall water splitting. Adv. Mater. 2016, 28, 3785-3790. [CrossRef] [PubMed]

13. Kim, J.Y.; Kim, H.; Kim, B.H.; Chang, T.; Lim, J.; Jin, H.M.; Mun, J.H.; Choi, Y.J.; Chung, K.; Shin, J.; et al. Highly tunable refractive index visible-light metasurface from block copolymer self-assembly. Nat. Commun. 2016, 7, 12911. [CrossRef] [PubMed]

14. Tang, C.; Zhang, R.; Lu, W.; He, L.; Jiang, X.; Asiri, A.M.; Sun, X. Fe-doped cop nanoarray: A monolithic multifunctional catalyst for highly efficient hydrogen generation. Adv. Mater. 2017, 29, 1602441. [CrossRef] [PubMed] 
15. Zhu, Y.-P.; Liu, Y.-P.; Ren, T.-Z.; Yuan, Z.-Y. Self-supported cobalt phosphide mesoporous nanorod arrays: A flexible and bifunctional electrode for highly active electrocatalytic water reduction and oxidation. Adv. Funct. Mater. 2015, 25, 7337-7347. [CrossRef]

16. Walter, M.G.; Warren, E.L.; McKone, J.R.; Boettcher, S.W.; Mi, Q.; Santori, E.A.; Lewis, N.S. Solar water splitting cells. Chem. Rev. 2010, 110, 6446-6473. [CrossRef]

17. Zadick, A.; Dubau, L.; Sergent, N.; Berthomé, G.; Chatenet, M. Huge instability of pt/c catalysts in alkaline medium. ACS Catal. 2015, 5, 4819-4824. [CrossRef]

18. Chen, Y.-Y.; Zhang, Y.; Jiang, W.-J.; Zhang, X.; Dai, Z.; Wan, L.-J.; Hu, J.-S. Pomegranate-like n,p-doped $\mathrm{mo}_{2} \mathrm{C} @ \mathrm{c}$ nanospheres as highly active electrocatalysts for alkaline hydrogen evolution. ACS Nano 2016, 10, 8851-8860. [CrossRef]

19. Chen, N.; Mo, Q.; He, L.; Huang, X.; Yang, L.; Zeng, J.; Gao, Q. Heterostructured moc-mop/n-doped carbon nanofibers as efficient electrocatalysts for hydrogen evolution reaction. Electrochim. Acta 2019, 299, 708-716. [CrossRef]

20. Zhang, X.; Yu, X.; Zhang, L.; Zhou, F.; Liang, Y.; Wang, R. Molybdenum phosphide/carbon nanotube hybrids as ph-universal electrocatalysts for hydrogen evolution reaction. Adv. Funct. Mater. 2018, 28, 1706523. [CrossRef]

21. Zhang, L.-N.; Li, S.-H.; Tan, H.-Q.; Khan, S.U.; Ma, Y.-Y.; Zang, H.-Y.; Wang, Y.-H.; Li, Y.-G. Mop/mo 2 @@c: A new combination of electrocatalysts for highly efficient hydrogen evolution over the entire ph range. ACS Appl. Mater. Interfaces 2017, 9, 16270-16279. [CrossRef] [PubMed]

22. Chinnappan, A.; Baskar, C.; Baskar, S.; Ratheesh, G.; Ramakrishna, S. An overview of electrospun nanofibers and their application in energy storage, sensors and wearable/flexible electronics. J. Mater. Chem. C 2017, 5, 12657-12673. [CrossRef]

23. Kumar, P.S.; Sundaramurthy, J.; Sundarrajan, S.; Babu, V.J.; Singh, G.; Allakhverdiev, S.I.; Ramakrishna, S. Hierarchical electrospun nanofibers for energy harvesting, production and environmental remediation. Energy Environ. Sci. 2014, 7, 3192-3222. [CrossRef]

24. Peng, S.; Jin, G.; Li, L.; Li, K.; Srinivasan, M.; Ramakrishna, S.; Chen, J. Multi-functional electrospun nanofibres for advances in tissue regeneration, energy conversion \& storage, and water treatment. Chem. Soc. Rev. 2016, 45, 1225-1241. [PubMed]

25. Chen, J.; Cheng, F. Combination of lightweight elements and nanostructured materials for batteries. Acc. Chem. Res. 2009, 42, 713-723. [CrossRef] [PubMed]

26. Liu, D.; Guo, Q.; Hou, H.; Niwa, O.; You, T. Pdxcoy nanoparticle/carbon nanofiber composites with enhanced electrocatalytic properties. ACS Catal. 2014, 4, 1825-1829. [CrossRef]

27. Kim, J.; Ghouri, Z.K.; Khan, R.Z.; An, T.; Park, M.; Kim,H.-Y. Experimental study on synthesis of co/ceo 2 -doped carbon nanofibers and its performance in supercapacitors. Carbon Lett. 2015, 16, 270-274. [CrossRef]

28. Laosiripojana, N.; Assabumrungrat, S. Catalytic steam reforming of ethanol over high surface area ceo $\mathrm{Cl}_{2}$ The role of $\mathrm{CeO}_{2}$ as an internal pre-reforming catalyst. Appl. Catal. B Environ. 2006, 66, 29-39. [CrossRef]

29. Sun, C.; Li, H.; Chen, L. Nanostructured ceria-based materials: Synthesis, properties, and applications. Energy Environ. Sci. 2012, 5, 8475-8505. [CrossRef]

30. Zhao, K.; Qi, J.; Yin, H.; Wang, Z.; Zhao, S.; Ma, X.; Wan, J.; Chang, L.; Gao, Y.; Yu, R.; et al. Efficient water oxidation under visible light by tuning surface defects on ceria nanorods. J. Mater. Chem. A 2015, 3, 20465-20470. [CrossRef]

31. Sivanantham, A.; Ganesan, P.; Shanmugam, S. A synergistic effect of co and $\mathrm{ceo}_{2}$ in nitrogen-doped carbon nanostructure for the enhanced oxygen electrode activity and stability. Appl. Catal. B Environ. 2018, 237, 1148-1159. [CrossRef]

32. Younis, A.; Chu, D.; Li, S. Oxygen level: The dominant of resistive switching characteristics in cerium oxide thin films. J. Phys. D Appl. Phys. 2012, 45, 355101. [CrossRef] 
33. Nguyen, T.-T.H.; Lee, J.; Bae, J.; Lim, B. Binary feco oxyhydroxide nanosheets as highly efficient bifunctional electrocatalysts for overall water splitting. Chem. Eur. J. 2018, 24, 4724-4728. [CrossRef] [PubMed]

34. Yu, L.; Zhou, H.; Sun, J.; Qin, F.; Yu, F.; Bao, J.; Yu, Y.; Chen, S.; Ren, Z. Cu nanowires shelled with nife layered double hydroxide nanosheets as bifunctional electrocatalysts for overall water splitting. Energy Environ. Sci. 2017, 10, 1820-1827. [CrossRef]

(C) 2020 by the authors. Licensee MDPI, Basel, Switzerland. This article is an open access article distributed under the terms and conditions of the Creative Commons Attribution (CC BY) license (http://creativecommons.org/licenses/by/4.0/). 